Acta Theriologica 40 (2): 145-162, 1995.

PL ISSN 0001-7051

\title{
Body mass and lower jaw development of the female red deer as indices of habitat quality in the Ardennes
}

\author{
Sabine B. BERTOUILLE and Simon A. de CROMBRUGGHE
}

\begin{abstract}
Bertouille S. B. and Crombrugghe S. A., de 1995. Body mass and lower jaw development of the female red deer as indices of habitat quality in the Ardennes. Acta Theriologica 40: $145-162$.

In order to investigate the most appropriate sampling to assess habitat effects on red deer, we analysed body mass, diastema length and length of the posterior part of the lower jaw of red deer females Cervus elaphus (Linnaeus 1758) in five study areas of the Ardennes (Belgium). Canonical discriminant analysis indicated that the female deer from the 5 study areas could be distinguished from each other on the basis of their body mass, diastema length and posterior length of the lower jaw. Body mass was the most correlated with the first canonical variable, while diastema length and posterior length of the lower jaw were less although significantly correlated. Age-specific comparisons of means indicated that variations in body mass, diastema length and posterior length of the lower jaw of yearlings and $\geq 4$-year-old females were the most effective to separate the different populations and hence were good indices of respectively short and long term variations in environmental conditions. Univariate comparison of means suggested that posterior length of the lower jaw of yearlings could be a valuable alternative to body weight as an indice of habitat quality. The Von Bertalanffy growth equation with $t_{0}$ fixed was used to assess the effect of habitat on asymptotic body mass and asymptotic jaw length and on the growth coefficients. The asymptotic values for body mass and jaw length were significantly higher where the habitat conditions appeared to be most favourable. In the poorest habitat, the growth of body mass and jaw length appeared slower, suggesting that female red deer, in this poorer habitat, could partially compensate their lower development as calves and yearlings by a longer growth period; however, only the growth coefficient of the posterior length of the lower jaw differed significantly from that of the best habitat.

Laboratoire de la Faune sauvage et de Cynégétique, Station de Recherches Forestières, avenue Maréchal Juin 23, B - 5030 Gembloux, Belgium, Fax 081-61 5727
\end{abstract}

Key-words: Cervus elaphus, body mass, growth curve, lower jaw

\section{Introduction}

In red deer Cervus elaphus (Linnaeus 1758) studies that related variations in size and body mass to a variation in habitat quality showed that body measurements are relevant indices of the general condition of a population in a certain habitat (Beninde 1937, Ahlen 1965, Mitchell et al. 1977, Buchli 1979, Clutton-Brock et al. 1982, Langvatn 1986, de Crombrugghe et al. 1989). Yet, as body measurements vary with age, corrections for age-effects are of first importance. Different approaches have been used to correct for age-effects: data have been 
analysed per age-class (Hesselton and Sauer 1973, Roseberry and Klimstra 1975); only for adults (Buchli 1979, Fandos and Vigal 1988); corrected using the residuals of a regression analysis with age as an independent variable (Langvatn and Albon 1986, Frampton and Nugent 1992); or using analysis of variance with age as a factor (Clutton-Brock and Albon 1983, Brisbin and Lenartz 1984). Another approach is the correction of a morphological measurement more sensitive to habitat differences by dividing it by another more stable measurement (leg bone length or size) (Klein 1964, Eiberle 1965, Gobbe 1971, Roseberry and Klimstra 1975).

Still another possibility is to fit a growth curve, describing the dynamics of the morphological measurement along an age gradient, and evaluate the effect of habitat quality on the parameters of the curve (Fendley and Brisbin 1977, Brisbin et al. 1986a, b, 1987). In large mammals, growth equations have also been used to investigate the evolution of growth with age (Western et al. 1983, Zullinger et al. 1984, Fandos and Vigal 1988, Fuller et al. 1989) and the effects of different factors on growth rate or size of animals have been assessed (Kingsley 1979, Chesser and Smith 1987, Leberg et al. 1992). However, although growth and development of red deer has often been described, neither data on growth curve parameters nor studies on the influence of different factors on these parameters have, to our knowledge, yet been published.

Previously we showed that, in male and female red deer calves $( \pm 6$ months old) from four areas of the Hautes-Fagnes (Ardennes), the body mass, the posterior length and the diastema length of the lower jaw, in decreasing order, were parameters influenced by differences in habitat quality and, hence, could be considered as ecological indices of the deer-habitat relationship (de Crombrugghe et al. 1989). Here, we extend our analysis to all age-classes in the female population, adding also data on a fifth habitat, considered as "excellent" according to the classification of Ueckermann (1960).

In this paper we (1) compare, using multivariate and univariate analyses, body mass, diastema length and posterior length of the lower jaw between habitats and age-classes, investigating whether some age-classes and measurements are more appropriate for studying habitat effects, (2) calculate separate growth curves per habitat, investigating the effects of habitat quality on the growth coefficient and the asymptotic value of these curves.

\section{Materials and methods}

Study areas

Four study areas (Elsenborn, Walhorn, Eupen and Hertogenwald), totalling 24000 ha, are situated in the 'Massif forestier des Hautes-Fagnes', eastern Belgium, at an altitude of 500 to $600 \mathrm{~m}$. The forests are dominated by Picea abies, with Sphagnum marshes, Calluna vulgaris, Vaccinium sp. and especially Molinia caerulea on the highest elevations. Details on the vegetation and management of the deer population are given in de Crombrugghe et al. (1989). A fifth study area of 4800 ha 


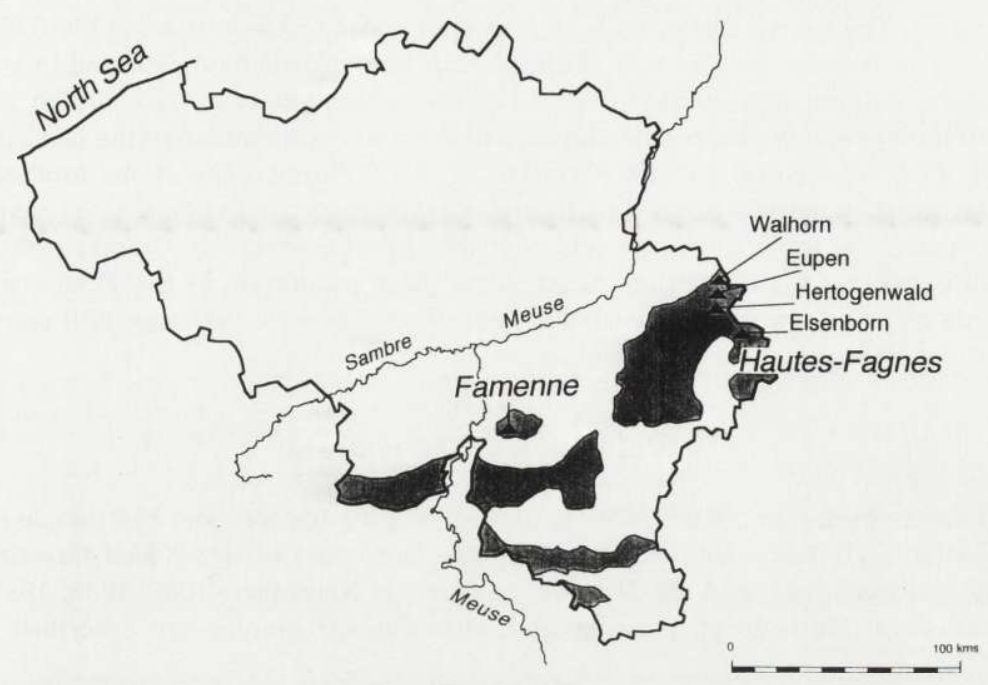

Fig. 1. Geographic distribution of red deer throughout Belgium (shaded areas) and location of the 5 study areas.

(Famenne) lies in the forest area of Haute-Lesse (Fig. 1). It is a mixed forest (70\% deciduous, $30 \%$ coniferous trees) dominated by Quercus petraea and Pinus sylvestris. Under the latter a rich undergrowth of Prunus spinosa, Crataegus oxyacantha, C. monogyna, Rosa spp. is present, providing an optimal deer habitat. Within the forest, open cultivated areas offer good feeding patches for red deer.

Table 1 gives for the five areas: the range quality value, the corresponding economic carrying capacity, the estimated density, and the percentage of overpopulation. The range quality value is calculated according to Ueckermann's (1960) rating system and is currently used in Western Europe as an index of forage availability both in quantity and quality; this index is based on four characteristics of the habitat: (1) quality of the substrate, (2) percentage of perimeter of the area facing cultivated lands, (3) percentage of area with open feeding grounds, and (4) tree species composition

Table 1. Range quality values and corresponding carrying capacity [according to Ueckermann's (1960) rating system]. The estimated density is obtained both from spring censuses and from population sizes deduced from annual deer culls.

\begin{tabular}{|c|c|c|c|c|}
\hline & \multicolumn{3}{|c|}{ 'Hautes-Fagnes' } & \multirow[b]{2}{*}{ Famenne } \\
\hline & Hertogenwald & Eupen and Walhorn & Elsenborn & \\
\hline Range quality value & $\begin{array}{c}45 \\
\text { ("low") }\end{array}$ & $\begin{array}{c}54 \\
\text { (“low") }\end{array}$ & $\begin{array}{c}62 \\
\text { ("middle") }\end{array}$ & $\begin{array}{c}73 \\
\text { ("high") }\end{array}$ \\
\hline $\begin{array}{l}\text { Carrying capacity } \\
\text { with winter feeding } \\
\text { ( } n / 1000 \text { ha on } 1 \text { April) }\end{array}$ & 30.0 & 32.5 & 35.0 & 40.0 \\
\hline $\begin{array}{l}\text { Estimated density } \\
\text { ( } n / 1000 \text { ha on } 1 \text { April) }\end{array}$ & 40.0 & 37.8 & 47.5 & 50.0 \\
\hline i.e. 'overpopulation' (\%) & 33 & 16 & 36 & 25 \\
\hline
\end{tabular}


of the forest area. The carrying capacity is that recommanded by Ueckermann (1960) if winter feeding is provided. The estimated density was obtained both from census data collected in spring and from population data deduced from annual deer culls. The percentage of overpopulation is calculated as follows: [(estimated density minus carrying capacity) $\times 100 /$ economic carrying capacity].

Detailed data concerning genetic variation of the different populations studied are lacking. However, the deer populations in the four Hautes-Fagnes areas are assumed to be genetically similar because of their geographic proximity and probable interbreeding (de Crombrugghe and Herman 1989). Significative genetic differences between the deer population of the Famenne area and the other populations could normally be excluded because of a general exchange still occurring between the different red deer populations of Belgium.

\section{Collection of the material}

Measurements were taken from 1359 adult and yearling females and 855 female calves between 15 September and 31 December (1982-1989) in the four areas of the Massif forestier des Hautes-Fagnes and between the end of October and end of November (1985, 1986, 1987 and 1989) in the Famenne area. Methods of shooting and collection of samples are described elsewhere (de

Table 2. Geographic and age-class distributions of animals for which at least one measure of body mass, diastema length or posterior part of the lower jaw was available.

\begin{tabular}{|c|c|c|c|c|c|c|c|c|c|c|c|c|}
\hline \multirow{2}{*}{ Area } & \multicolumn{11}{|c|}{ Age-class (years) } & \multirow{2}{*}{ Total } \\
\hline & 0 & 1 & 2 & 3 & 4 & 5 & 6 & 7 & 8 & 9 & 10 & \\
\hline Famenne & 42 & 24 & 21 & 23 & 13 & 7 & 0 & 3 & 0 & 0 & 1 & 134 \\
\hline Elsenborn & 344 & 165 & 150 & 59 & 43 & 28 & 27 & 19 & 13 & 17 & 10 & 875 \\
\hline Eupen & 220 & 112 & 46 & 30 & 21 & 18 & 24 & 13 & 10 & 14 & 13 & 521 \\
\hline Hertogenwald & 89 & 48 & 32 & 10 & 3 & 4 & 12 & 9 & 5 & 10 & 6 & 228 \\
\hline Walhorn & 160 & 103 & 67 & 34 & 22 & 11 & 13 & 15 & 13 & 12 & 6 & 456 \\
\hline Total & 855 & 452 & 316 & 156 & 102 & 68 & 76 & 59 & 41 & 53 & 36 & 2214 \\
\hline
\end{tabular}

Crombrugghe et al. 1989). The following measurements were used: (1) field dressed weight (BM): eviscerated body mass with head, to the nearest $1 \mathrm{~kg}$ (Langvatn 1977); (2) diastema length (DL): distance between the most anterior point of the socket of the anterior premolar and the most posterior point of the socket of the corner incisor; (3) posterior length of the lower jaw (PL): was obtained by substracting DL from the total length (TL) of the lower jaw; TL was measured from the most posterior point of the socket of the corner incisor to the most posterior rim of the angle of ramus ascendens. Skeletal measurements were taken to the nearest $0.1 \mathrm{~mm}$ using calipers.

All animals were aged according to age-classes based on tooth eruption and wear (Müller-Using 1976, de Crombrugghe 1976) (Table 2). For use in growth curves, age in days was determined using the mean parturition date of 1 June (Rieck 1955) and the date the animals were culled.

\section{Age specific differences between deer in different habitats}

Since the mean culling date varied significantly between areas, data for calves collected during a period of fast growth, had to be corrected so that all weights and jaw measurements referred to the same age. Corrections would be made by the same procedure as in de Crombrugghe et al. 1989: 


$$
\begin{array}{ll}
\mathrm{BM}_{\text {adjusted }}=\mathrm{BM}+[161-\text { age }(\text { days })] \times 0.049 & \mathrm{BM} \text { in } \mathrm{kg} \\
\mathrm{DL} \text { adjusted }=\mathrm{DL}+[161-\text { age }(\text { days })] \times 0.4872 & \mathrm{DL} \text { in cm } \\
\mathrm{PL}_{\text {adjusted }}=\mathrm{PL}+[161-\text { age }(\text { days })] \times 1.1517 & \mathrm{PL} \mathrm{in} \mathrm{cm}
\end{array}
$$

(161 corresponds to the age in days at the mean culling date). Adult animals of four years and over were grouped in one class ( $\geq 4$ year). No animal was included in the analysis unless the three measurements were available.

Effects of area, age, year and their interactions, on body mass, diastema length and posterior length of the lower jaw taken together, were analysed using an unbalanced three-way multivariate analysis of variance (MANOVA in GLM subroutine of SAS 1985). Canonical discriminant analysis on data combined across years was performed for each age-class separately (CANDISC subroutine of SAS 1985). Comparisons between habitats were based on the Mahalanobis distance.

Because one or the other of the three measurements could be missing, effects of area, age, year and their interactions were also assessed on body mass, diastema length and posterior length of the lower jaw taken separately, using an unbalanced three-way univariate analyses of variance (GLM subroutine of SAS 1985). Effects of area for data combined across years, were assessed for each age-class separately with a one-way ANOVA. Differences between habitats were tested using a SCHEFFE-test (Sokal and Rohlf 1981).

\section{Differences between habitats in growth curves}

To fit the body mass-age and jaw length-age data, we tested three growth models, with successively four, three and two estimated parameters. The growth model used is the reparameterized Richards equation (Brisbin et al. 1986a) with four parameters, and with successively one and two fixed parameters. The reparameterized Richards equation is:

$$
W_{t}=\left[W_{\infty}^{(1-m)}-\left(W_{\infty}^{(1-m)}-W_{0}^{(1-m)}\right) \times \exp ^{(-2 \times t / \mathrm{T}) \times(1+m)}\right]^{1 /(1-m)}
$$

where: $W_{t}$ - the body mass or jaw length at age $t, W_{\infty}-$ the asymptotic mass or length, $\mathrm{T}-$ the growth period indicative of growth rate (Brisbin et al. 1986a, Leberg et al. 1989), $W_{0}$ - the birth mass or birth length, and $m$ - the Richards shape parameter.

The second model is a particular case of the Richards function, where $m$ has a fixed value of 0.67 (Richards 1959, Brisbin et al. 1986a) and corresponds to the Von Bertalanffy equation. This equation may also be written:

$$
W_{t}=W_{\infty}\left(1-\exp ^{-k\left(t-t_{0}\right)}\right)
$$

where: $W_{t}$ - the body mass or the jaw length at age $t, W_{\infty}$ - the asymptotic body mass or jaw length, $k$ - a growth-coefficient, and $t_{0}$ - the age (in years) at which body mass or jaw length is supposed to be 0 , i.e. related to the conception date.

In the third model, we fixed $t_{0}$ at -0.6538 , corresponding to the gestation period of 34 weeks (in years) (Thome 1980, Von Raesfeld 1964), because values of $t_{0}$ were difficult to determine precisely (Frampton and Nugent 1992), and therefore we reduced the Von Bertalanffy equation to two parameters:

$$
W_{t}=W_{\infty}\left(1-\exp ^{-k(t+0.6538)}\right)
$$

The reparameterized Richards equation (four parameters), the Von Bertalanffy equation (three parmeters) and the " $t_{0}$ fixed" Von Bertalanffy equation (two parameters) were fitted to mass-age data and jaw length-age data using the NLIN subroutine of SAS (1985). The secant method (DUD) of iteration was used to obtain estimates of the parameters.

The $F$-test (White and Brisbin 1980) was used to determine if curves differed between habitats. If differences were detected, a second $F$-test was used to determine whether the difference was due to $W_{\infty}$ or $T$ (equation 1) or $W_{\infty}$ or $k$ (equations 2 and 3) (White and Brisbin 1980, Leberg et al. 1992). 


\section{Results}

\section{Differences between deer in different habitats}

The mean culling date varied significantly between areas $\left(F_{4,2209}=74.67\right.$, $p \leq 0.0001$ ) and data for calves have been adjusted to a mean age of 161 days. Multivariate analysis of variance showed highly significant effects of age, area, year and their 2- and 3-factors interactions (Table 3). Since the effects due to annual variation, age-year, area-year and age-area-year interactions were very small compared with age and area effects, data were combined across years in the following analyses. In order to investigate whether some age-classes are more appropriate to study area effects and because of the significant age-area interaction, we tested for differences between areas for each age class separately. Differences between areas for BM, PL and DL taken together, was highly significant for each age class (Table 4). The first canonical variable explained 88

Table 3. Comparison of body mass (BM), diastema length (DL) and posterior length (PL) of the lower jaw of female deer between areas, ages, years and their interactions using a three-way MANOVA [degrees of freedom, $F$ values (WILKS' criterion) and associated probabilities] and three-way ANOVA (degrees of freedom, SNEDECOR's $F$ ratio and associated probabilities).

\begin{tabular}{|c|c|c|c|c|c|c|c|c|c|c|}
\hline \multirow{2}{*}{ Factor } & \multicolumn{3}{|c|}{ BM-DL-PL } & \multirow[b]{2}{*}{ df } & \multicolumn{2}{|c|}{ BM } & \multicolumn{2}{|c|}{ DL } & \multicolumn{2}{|c|}{ PL } \\
\hline & df & $F$ & $p>F$ & & $F$ & $p>F$ & $F$ & $p>F$ & $F$ & $p>F$ \\
\hline Age & 12,3688 & 460.05 & 0.001 & 4,1396 & 917.06 & 0.001 & 891.21 & 0.001 & 3166.0 & 0.001 \\
\hline Area & 12,3688 & 25.98 & 0.001 & 4,1396 & 78.68 & 0.001 & 19.55 & 0.001 & 17.52 & 0.001 \\
\hline Year & 21,4003 & 2.40 & 0.001 & 7,1396 & 3.80 & 0.001 & 2.06 & 0.045 & 2.36 & 0.022 \\
\hline Age $\times$ Area & 48,4146 & 2.04 & 0.001 & 16,1396 & 2.12 & 0.006 & 0.91 & 0.556 & 1.94 & 0.015 \\
\hline Age $\times$ Year & 84,4171 & 1.52 & 0.002 & 28,1396 & 1.52 & 0.041 & 1.61 & 0.023 & 1.63 & 0.021 \\
\hline Area $\times$ Year & 72,4166 & 1.47 & 0.006 & 24,1396 & 1.49 & 0.061 & 1.97 & 0.004 & 1.42 & 0.086 \\
\hline Age $\times$ Area $\times$ Year & 267,4181 & 1.24 & 0.007 & 89,1396 & 1.05 & 0.357 & 1.04 & 0.384 & 1.26 & 0.055 \\
\hline
\end{tabular}

Table 4. Comparison of body mass (BM), diastema length (DL) and posterior length of the lower jaw (PL) of female deer between areas, using a one-way MANOVA [degrees of freedom, $F$ values (WILKS' criterion) and associated probabilities] and one-way ANOVA (degrees of freedom, SNEDECOR's $F$ ratio and associated probabilities) for each age-class.

\begin{tabular}{|c|c|c|c|c|c|c|c|c|c|c|}
\hline \multirow{2}{*}{$\begin{array}{l}\text { Age- } \\
\text {-class }\end{array}$} & \multicolumn{3}{|c|}{ BM-DL-PL } & \multirow[b]{2}{*}{ df } & \multicolumn{2}{|c|}{$\mathrm{BM}$} & \multicolumn{2}{|c|}{ DL } & \multicolumn{2}{|c|}{ PL } \\
\hline & $\mathrm{df}$ & $F$ & $p>F$ & & $F$ & $p>F$ & $F$ & $p>F$ & $F$ & $p>F$ \\
\hline 0 & 12,1550 & 10.4 & 0.001 & 4,588 & 28.38 & 0.001 & 12.01 & 0.001 & 20.31 & 0.001 \\
\hline 1 & 12,807 & 11.8 & 0.001 & 4,307 & 34.06 & 0.001 & 6.97 & 0.001 & 15.89 & 0.001 \\
\hline 2 & 12,545 & 5.1 & 0.001 & 4,208 & 13.61 & 0.001 & 2.00 & 0.096 & 3.89 & 0.005 \\
\hline 3 & 12,309 & 6.8 & 0.001 & 4,119 & 21.79 & 0.001 & 8.26 & 0.001 & 4.34 & 0.003 \\
\hline 4 & 12,846 & 10.3 & 0.001 & 4,322 & 30.14 & 0.001 & 5.24 & 0.001 & 4.63 & 0.002 \\
\hline
\end{tabular}


to $97 \%$ of the variability (Table 5) and was most correlated with BM, less (but still significantly) so with DL and PL. PL was the second more correlated variable

Table 5. Proportion of variability explained by the first and the second canonical variables for each age-class.

\begin{tabular}{lcc}
\hline Age-class & CAN1 & CAN2 \\
\hline 0 & 0.97 & 0.03 \\
1 & 0.88 & 0.11 \\
2 & 0.88 & 0.12 \\
3 & 0.96 & 0.03 \\
$\geq 4$ & 0.90 & 0.08 \\
\hline
\end{tabular}

Table 6. Coefficient of correlation between each variable (body mass, diastema length and posterior length of the lower jaw) and the first canonical variable for each age-class.

\begin{tabular}{lccccc}
\hline \multirow{2}{*}{ Variable } & \multicolumn{5}{c}{ Age-class } \\
\cline { 2 - 6 } & 0 & 1 & 2 & 3 & $\geq 4$ \\
\hline BM & 0.94 & 0.99 & 0.98 & 0.97 & 0.99 \\
DL & 0.66 & 0.51 & 0.29 & 0.71 & 0.45 \\
PL & 0.84 & 0.71 & 0.57 & 0.52 & 0.38 \\
\hline
\end{tabular}

Table 7. Mean body mass (BM), mean diastema length (DL), mean posterior length of the lower jaw (PL) for the 5 study areas, ranked in decreasing order, for each age-class. Area means of body mass, diastema length and posterior length of the lower jaw on the first canonical variable, ranked in decreasing order, for each age-class. Interrupted lines beside the values indicate significant differences between areas $(p<0.05)$.

\begin{tabular}{|c|c|c|c|c|c|c|c|c|}
\hline \multirow{2}{*}{$\begin{array}{l}\begin{array}{l}\text { Age-class } \\
\text { (years) }\end{array} \\
0\end{array}$} & \multicolumn{2}{|c|}{ BM (kg) } & \multicolumn{2}{|c|}{$\mathrm{DL}(\mathrm{cm})$} & \multicolumn{2}{|c|}{ PL (cm) } & \multicolumn{2}{|c|}{ BM-DL-PL } \\
\hline & FAM & 41.9 | & FAM & 6.27 & FAM & 13.24 | & FAM & $1.25 \mid$ \\
\hline & ELS & 36.8 & ELS & 6.07 & ELS & 12.82 & ELS & 0.27 \\
\hline & WALH & 35.6 & WALH & 5.99 & WALH & 12.69 & WALH & -0.0004 \\
\hline & EUP & 34.6 & EUP & 5.92 & EUP & 12.66 & EUP & -0.14 \\
\hline & HERT & 30.9 | & HERT & 5.76 & HERT & $11.28 \mid$ & HERT & $-0.91 \mid$ \\
\hline \multirow[t]{5}{*}{1} & FAM & 65.5 । & FAM & $7.77 \mid$ & FAM & $16.39 \mid$ & FAM & $1.90 \mid$ \\
\hline & ELS & 55.8 & ELS & 7.37 & WALH & 15.87 & ELS & $0.42 \mid$ \\
\hline & WALH & 52.9 & WALH & 7.31 & ELS & 15.79 & WALH & 0.04 \\
\hline & EUP & 51.0 & EUP & 7.30 & EUP & 15.69 & EUP & -0.28 \\
\hline & HERT & $46.7 \mid$ & HERT & 7.09 & HERT & $15.21 \mid$ & HERT & $-0.99 \mid$ \\
\hline \multirow[t]{5}{*}{2} & FAM & $69.1 \mid$ & FAM & 7.80 & FAM & 17.33 & FAM & $1.09 \mid$ \\
\hline & ELS & 63.3 & ELS & 7.63 & ELS & 17.20 & ELS & 0.33 \\
\hline & WALH & 60.5 & EUP & 7.60 & WALH & 17.10 & WALH & -0.007 \\
\hline & EUP & 58.3 & WALH & 7.47 & EUP & 16.88 & EUP & -0.45 \\
\hline & HERT & 55.1 & HERT & 7.45 & HERT & 16.80 & HERT & -0.84 \\
\hline \multirow[t]{5}{*}{3} & FAM & 79.5 | & FAM & $8.55 !$ & FAM & 18.03 & FAM & $1.81 \mid$ \\
\hline & WALH & 66.0 & WALH & 8.01 & HERT & 17.58 & WALH & -0.17 \\
\hline & ELS & 65.5 & ELS & 8.01 & WALH & 17.58 & ELS & -0.23 \\
\hline & HERT & 65.1 & HERT & 7.86 & EUP & 17.50 & HERT & -0.39 \\
\hline & EUP & 60.8 & EUP & 7.85 & ELS & 17.49 & EUP & -0.89 \\
\hline \multirow[t]{5}{*}{$\geq 4$} & FAM & $79.5 \mid$ & FAM & 8.77 । & FAM & 18.07 & FAM & $1.93 \mid$ \\
\hline & ELS & 68.1 & WALH & 8.44 & ELS & 17.87 & ELS & $0.31 \mid$ \\
\hline & WALH & 64.6 & ELS & 8.40 & WALH & 17.87 & WALH & -0.14 \\
\hline & EUP & 63.8 & EUP & 8.31 & EUP & 17.83 & EUP & -0.28 \\
\hline & HERT & 60.4 & HERT & 8.19 & HERT & 17.49 & HERT & $-0.77 \mid$ \\
\hline
\end{tabular}


for the 0-, 1- and 2-year-old classes and DL for the 3- and $\geq 4$-year old classes respectively (Table 6). For yearlings only, the second canonical variable was also significant and was the most correlated with PL. Yearlings and $\geq 4$-year-old female deer of the different areas could be separated on basis of BM, DL and PL in four significantly different groups classified in the following order (Table 7): Famenne $>$ Elsenborn $>$ Walhorn $=$ Eupen $>$ Hertogenwald .

Age-class, area and year affected also significantly each of the three variables taken separately (Table 3). A significant age-area interaction was found for BM and PL but not for DL, age-year interaction was significant for the three measurements and area-year interaction was significant for DL and PL but not for BM. The 3-factors interaction was not significant for any of the three variables. Between area variation in BM was highly significant for all age classes (Table 4). Both jaw measurements (DL and PL) showed a larger between area variation for calves and yearlings, while other age-class differences were smaller, but still significant, except for DL of 2-year olds (Table 4). Calves and yearlings can be divided into three groups, based on BM or PL (Table 7). They are largest and heaviest in Famenne, intermediate at Elsenborn, Walhorn and Eupen, and smallest and lightest at Hertogenwald. Yearlings from Elsenborn also weighed significantly more than those from Eupen.

\section{Differences between habitats in growth curves}

Growth model

The fitting of our data was better with the reparameterized Richards equation with four parameters than with the Von Bertalanffy equation with three parameters or with the "to fixed" Von Bertalanffy equation with two parameters. Yet, the accuracy of the estimated parameters decreased greatly with an increasing number of estimated parameters, especially for the parameters other than the asymptotic mass or length.

A significant effect of habitat on the three growth curves and on asymptotic mass or asymptotic length were obtained, independently of the growth model used. The effect of habitat on the growth coefficient appeared similar when data were fitted with the reparameterized Richards equation (1) or with the "to fixed" Von Bertalanffy equation (3) but differed from results obtained when data were fitted with the Von Bertalanffy equation (2).

The growth parameters $T, m$ and $W_{0}$ of the Richards equation (1) and the growth parameters $k$ and $t_{0}$ of the Von Bertalanffy equation (2) were higly intercorrelated, with $r=0.925$ to 0.999 . Fitting the DL-age data appeared to be very hazardous (with the Richards equation particularly), since the parameters were very difficult to estimate, depending greatly upon the starting values of the iteration so that estimated values were quite uninterpretable.

Consequently, in the remaining part of this paper, only results obtained with the "to fixed" Von Bertalanffy equation (3) will be presented. 
Differences between habitats in growth curves

The BM-age and the (DL and $\mathrm{PL}$ ) jaw length-age regression equations were different between habitats (BM-age: $F_{8}, 2124=77.1, p \leq 0.0001$; DL-age: $F_{8}, 2073=11.4$, $p \leq 0.0001$; PL-age: $F_{8}, 1618=15.2, p \leq 0.0001$ ) (Fig. $2 \mathrm{a}, \mathrm{b}, \mathrm{c}$ ). Female deer from
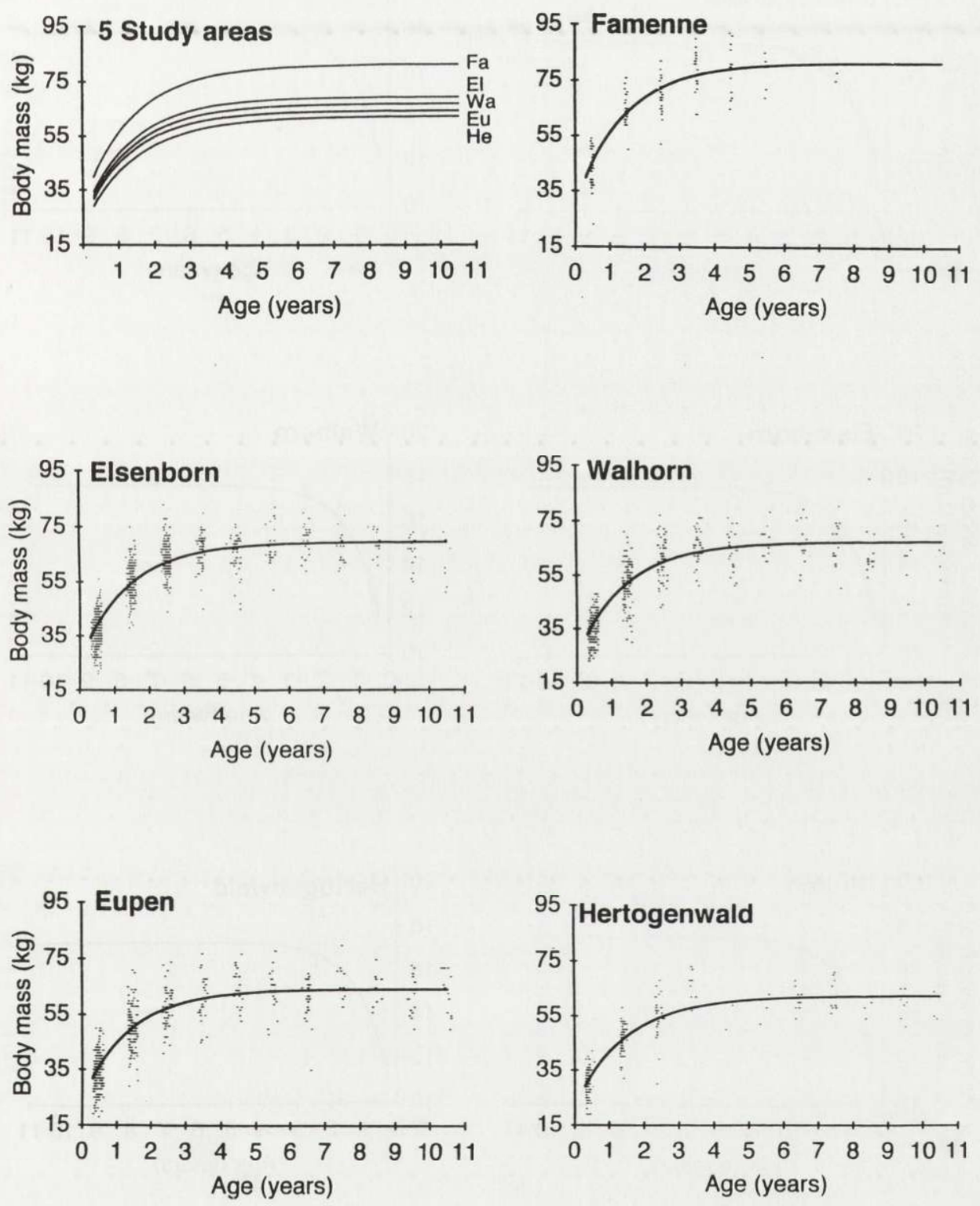

Fig. 2a. Top left: $t_{0}$ fixed Von Bertalanffy growth curves fit to individual measurements of body mass of female red deer for the 5 study areas in Belgium: Famenne (Fa), Elsenborn (El), Walhorn (Wa), Eupen (Eu) and Hertogenwald (He). Next figures: for each study area, the $t_{0}$ fixed Von Bertalanffy growth curve is shown with the body mass plotted against age. 
different habitats had a different asymptotic BM $\left(F_{4,2124}=60.9, p \leq 0.0001\right)$ but their body mass growth coefficients $(k)$ were not significantly different $\left(F_{4,2124}=\right.$ $1.006, p=0.403$ ). Estimates of asymptotic BM were significantly larger in Famenne
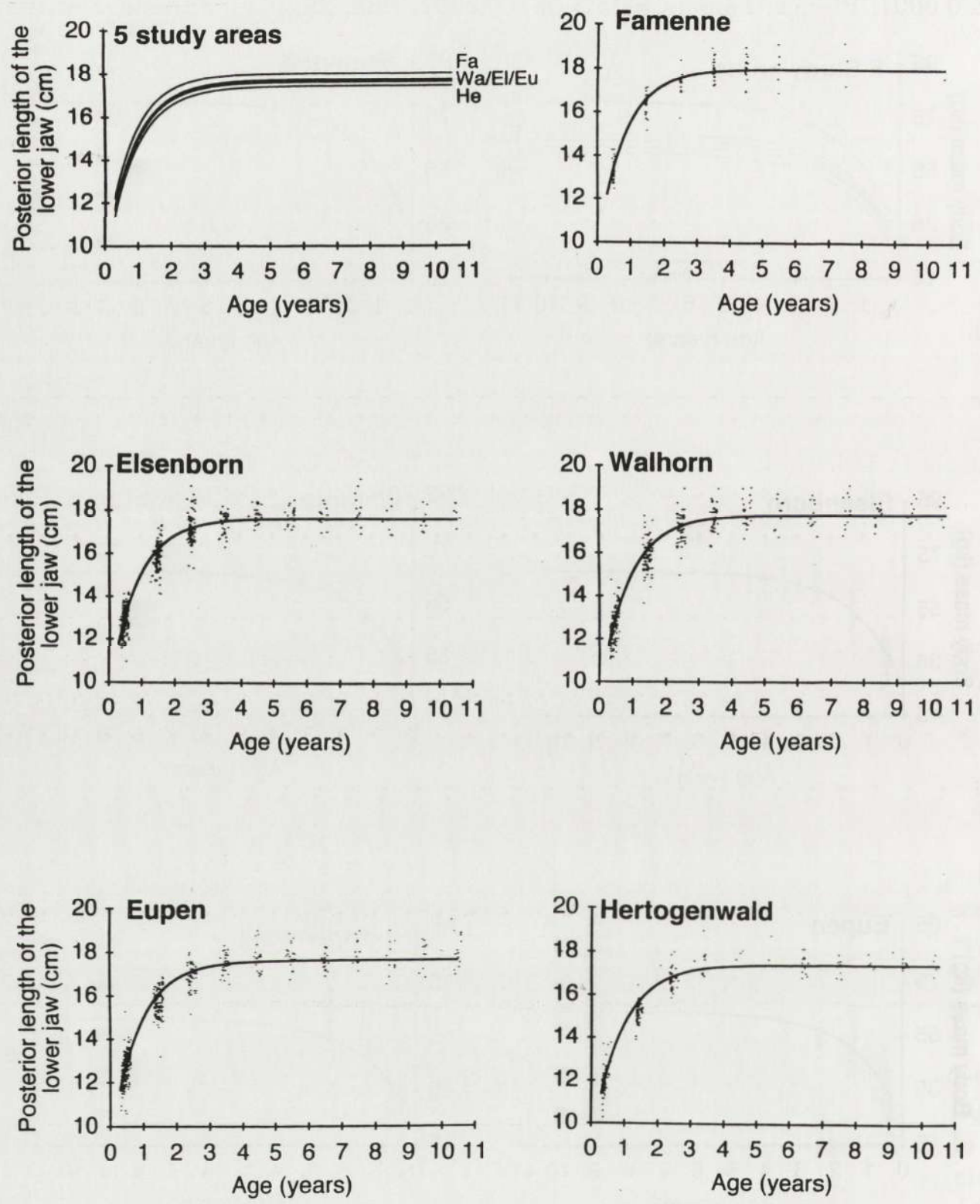

Fig. 2b. Top left: $t_{0}$ fixed Von Bertalanffy growth curves fit to individual measurements of diastema length of the lower jaw of female red deer for the 5 study areas (see Fig. 2a). Next figures: for each study area, the $t_{0}$ fixed Von Bertalanffy growth curve is shown with the diastema length of the lower jaw plotted against age. 
than in Elsenborn which had a higher value than Walhorn and Eupen (Table 8). Finally Hertogenwald differed significantly from Walhorn.
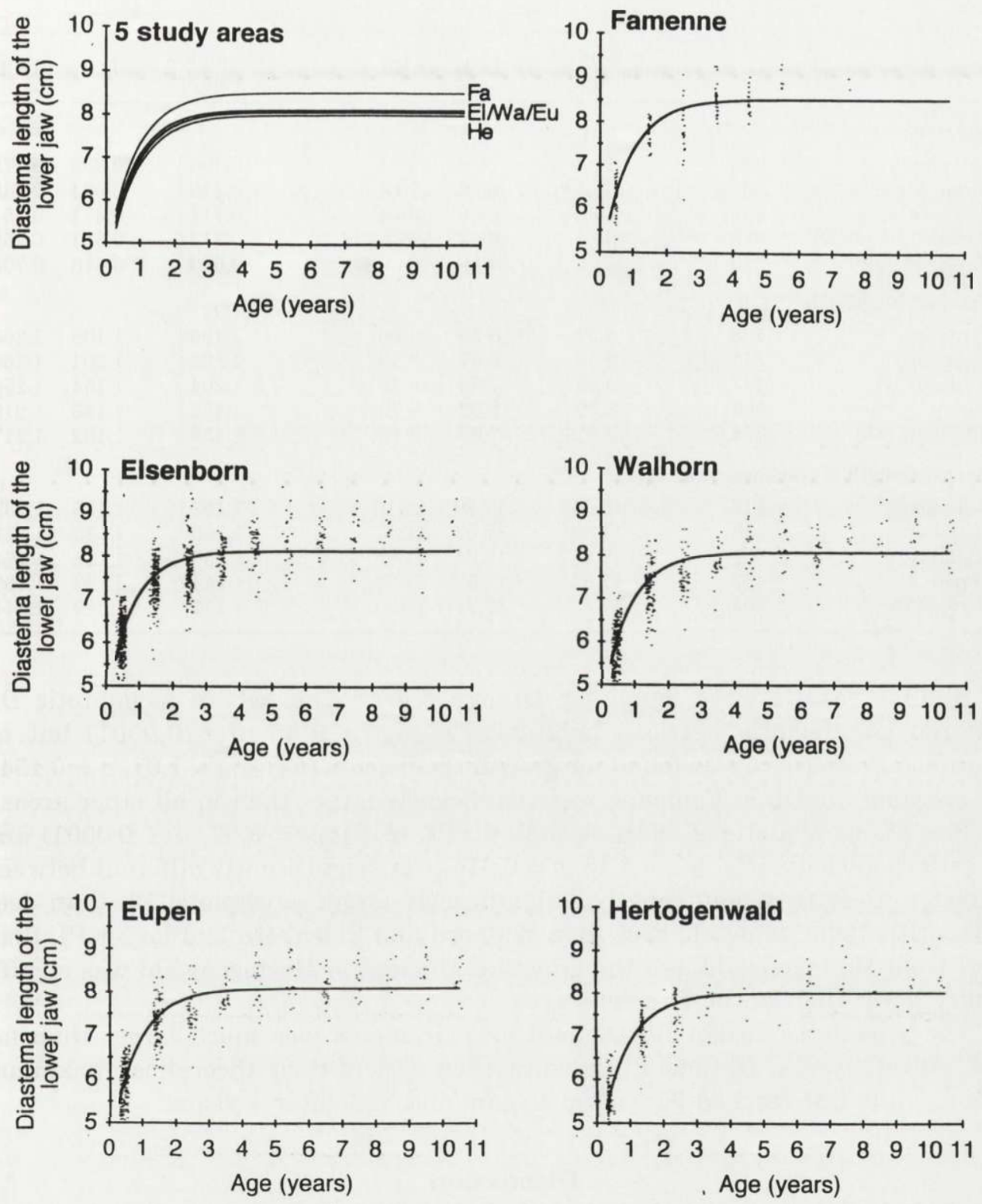

Fig. 2c. Top left: $t_{0}$ fixed Von Bertalanffy growth curves fit to individual measurements of posterior length of the lower jaw of female red deer for the 5 study areas (see Fig. 2a). Next figures: for each study area, the $t_{0}$ fixed Von Bertalanffy growth curve is shown with the posterior length of the lower jaw plotted against age. 
Table $8 . W_{\infty}$ and $k$ parameter of Von Bertalanffy equation with lower (LCL) and upper (UCL) limit of the $95 \%$ confidence intervals for body mass, diastema length and posterior length of lower jaw. Interrupted lines beside the values indicate significant differences between areas $(p<0.05)$.

\begin{tabular}{|c|c|c|c|c|c|c|c|}
\hline & \multirow[b]{2}{*}{$n$} & \multicolumn{3}{|c|}{$W_{\infty}$} & \multicolumn{3}{|c|}{$k$} \\
\hline & & $\begin{array}{c}\text { estimated } \\
\text { value }\end{array}$ & LCL & UCL & $\begin{array}{c}\text { estimated } \\
\text { value }\end{array}$ & LCL & UCL \\
\hline \multicolumn{8}{|l|}{ Body mass (kg) } \\
\hline Famenne & 134 & $81.4 \mid$ & 78.6 & 84.1 & 0.706 & 0.636 & 0.775 \\
\hline Elsenborn & 833 & $69.5 \mid$ & 68.5 & 70.4 & 0.719 & 0.694 & 0.745 \\
\hline Walhorn & 446 & 67.0 & 65.6 & 68.4 & 0.711 & 0.671 & 0.751 \\
\hline Eupen & 509 & $64.4 \mid$ & 63.2 & 65.6 & 0.717 & 0.681 & 0.752 \\
\hline Hertogenwald & 216 & 62.3 & 60.6 & 64.0 & 0.663 & 0.618 & 0.708 \\
\hline \multicolumn{8}{|c|}{ Diastema length $(\mathrm{cm})$} \\
\hline Famenne & 128 & $8.52 \mid$ & 8.39 & 8.66 & 1.186 & 1.108 & 1.265 \\
\hline Elsenborn & 811 & 8.13 & 8.07 & 8.18 & 1.233 & 1.201 & 1.266 \\
\hline Walhorn & 437 & 8.08 & 7.99 & 8.16 & 1.204 & 1.154 & 1.253 \\
\hline Eupen & 502 & 8.09 & 8.02 & 8.16 & 1.182 & 1.145 & 1.219 \\
\hline Hertogenwald & 208 & 8.01 & 7.90 & 8.12 & 1.159 & 1.102 & 1.217 \\
\hline \multicolumn{8}{|c|}{ Posterior length of the lower jaw $(\mathrm{cm})$} \\
\hline Famenne & 117 & $18.01 \mid$ & 17.86 & 18.16 & 1.197 & 1.155 & 1.239 \\
\hline Elsenborn & 480 & 17.68 & 17.59 & 17.77 & 1.156 & 1.135 & 1.177 \\
\hline Walhorn & 359 & 17.74 & 17.64 & 17.85 & 1.138 & 1.112 & 1.164 \\
\hline Eupen & 472 & 17.62 & 17.52 & 17.71 & 1.144 & 1.123 & 1.165 \\
\hline Hertogenwald & 204 & 17.43 & 17.31 & 17.55 & 1.117 & 1.089 & 1.144 \\
\hline
\end{tabular}

Similar results were found for DL-age regressions, where asymptotic DL differed significantly between habitats $\left(F_{4}, 2073=9.35, p \leq 0.0001\right)$ but no significant difference was found for growth coefficients $\left(F_{4,2073}=1.67, p=0.154\right)$. The asymptotic DL in Famenne was significantly larger than in all other areas.

For PL-age equations, both asymptotic PL $\left(F_{4}, 1618=8.57, p \leq 0.0001\right)$ and growth coefficients $\left(F_{4}, 1618=3.15, p=0.014\right)$ were significantly different between habitats. Deer from Famenne had significantly larger asymptotic PL than deer from other habitats, while deer from Walhorn and Elsenborn had larger PL than deer from Hertogenwald and the growth coefficient in Hertogenwald was significantly lower than in the Famenne area.

The growth coefficient for skeletal measurements was much larger than for BM. After 2 years, DL and PL have reached 97\% of their theoretical maximum value, while BM reached $95 \%$ after 3 years and $97 \%$ after 4 years.

\section{Discussion}

Body measurements as age dependent condition indicators

Body mass (BM), posterior length of the lower jaw (PL) and diastema length (DL) of female red deer differed significantly between habitats both in uni- and 
multivariate analyses and this was true for all age classes, except for DL in 2 -year-old females. However, measurements on 2- and 3-year-old female red deer were less successful in distinguishing habitats. This might be due to the critical criteria used for the age determination of our 2 and 3 year-old red deer (dental development and tooth-wear), which are different from those used for red deer from Rhum (Lowe 1967). We observed personally a few male red deer 3 years of age, whose age had heen determined using cemental annuli counts, that presented tooth-wear and even tooth eruption characteristics of 2-year-old animals.

Differences between areas were most obvious when comparing the three variables together, with $\mathrm{BM}$ showing the highest correlation with the first canonical variable. Inter-area differences were most pronounced in calves and yearlings and, for the multivariate analysis only, in 4-year-old females.

Hence, long term effects of habitat quality on red deer could be studied using multivariate analysis of BM, PL and DL of 4-year-old females. For short-term effects of habitat quality on red deer, analyses should be limited to calves and yearlings.

Because the indication of the sex of calves reported on the culling-form is not always fully reliable and because of the necessity to adjust data relating to calves with regard to the date on which they were shot, yearling females represent the most appropriate age-class for the comparison of red deer populations living in different habitats. This is true not only for multivariate comparisons but also for BM and PL taken separately.

Considering, furthermore, that the measurement of $\mathrm{BM}$ in field conditions is not always reliable, the measuring in laboratory conditions of PL on yearling jaws appears to be a valuable alternative as an indice of habitat effects on red deer. Clutton-Brock et al. (1982) also found a higher sensitivity of calves and especially yearlings to environmental conditions, with increased mortality of both age-classes after harsh winters. According to Illius and Gordon (1990), yearlings, having only one pair of adult incisors, should have a lower feeding efficiency on depleted resources than calves and especially adults with complete dentition. It is also this yearling-class that reacts most distinctly in terms of reproductive rate in response to increasing food availability (de Crombrugghe 1964). Red deer yearlings thus appear to be the most suitable indicators of population condition.

\section{Growth curves as condition indicators}

The reparameterized Richards equation with four parameters was used to fit our data because this curve, with its shape parameter $m$, and thus its flexibility, appeared to be more adequate to fit data compared with other models in which the curve shape is fixed (Brisbin et al. 1986a). However, on the one hand, accuracy of the estimated parameters decreases with increasing number of estimated parameters; this is of particular importance since differences in the effects of habitat on growth were assessed by comparing the growth parameters estimated for deer collected from the five habitats. On the other hand, the growth parameters 
$T, m$ and $W_{0}$ [reparameterized Richards equation (1)] and $k$ and $t_{0}$ [Von Bertalanffy equation (2)] were higly intercorrelated, so that little confidence can be placed in the estimates of these parameters (Debouche 1977) and that comparisons of growth coefficients between habitats are dubious. Moreover, values of $m$ and $W_{0}$ were aberrant and without possible interpretation. Leberg et al. $(1989,1992)$ suggested that asymptotic mass $\left(W_{\infty}\right)$ and growth period $(T)$ obtained from the Richards equation were relatively insensitive to nonuniform sampling and aging errors associated with harvest data collection but that the shape parameter $m$ and $W_{0}$ may be imprecise and biased and usually overestimated. Nevertheless, they thought that by allowing these parameters to vary, the estimates of $W_{\infty}$ and $T$ were improved (Leberg et al. 1992). However, because the values of $T$ obtained with our data were highly correlated with $m$ and $W_{0}$, these $T$ values appeared also very imprecise and biased. Hence, with the Von Bertalanffy equation (3), the estimate of the growth coefficient $k$ could have been influenced by the fixed shape $\mathrm{m}$ and $t_{0}$ (Brisbin et al. 1986a, b) and estimates of $W_{\infty}$ and $\mathrm{T}$ obtained from the Richards equation appeared less sensitive to nonuniform sampling and aging errors than estimates obtained from the Von Bertalanffy equation (2) (Leberg et al. 1989). Consequently, the greatest care must be taken in interpreting the growth coefficient estimates, obtained with the reparameterized Richards equation as well as with the Von Bertalanffy equation. However, quite similar results were obtained with both models: the growing periods of BM and PL of female deer from Hertogenwald were longer than those of female deer of other habitats, with significant differences for PL although confidence intervals overlapped in the case of the reparameterized Richards equation (1). Asymptotic values of BM and PL obtained from the reparameterized Richards equation (1) were respectively 0.5 to $2.5 \mathrm{~kg}$ lower and 0.06 to $0.37 \mathrm{~cm}$ longer than values obtained from the " $t_{0}$ fixed" Von Bertalanffy equation (3) but habitats could be ranked in the same order independently of the growth model used, although significant grouping was somewhat different.

In most mammals, skeletal growth ends more rapidly than muscular growth or formation of fat tissue [(McMeekan 1940a, b, Palson and Verges 1952) quoted in Langvatn 1977]. In our red deer, skeletal growth of females was almost completed at 2-years of age, while body mass continued to increase up to 3-4 years of age. Most studies agree that red deer females reach maximum body mass when 3-4 years old (Gobbe 1971, Mitchell et al. 1977, Buchli 1979, Langvatn and Albon 1986, Maillard et al. 1989), although for red deer females living in a poor habitat authors found an increase in body mass up to 5-6 years of age [Lowe 1971, Illius and Gordon 1990, (Klein quoted in Teillaud et al. 1991)].

The attainment of higher body mass or higher skeletal development and more rapid growth are generally considered to be indicative of individuals in good condition living in good environmental conditions. Female deer from Famenne had largest asymptotic values of BM, DL and PL, significantly different from those found in the four other areas, while the asymptotic values from Hertogenwald 
were the smallest and those from Elsenborn, Walhorn and Eupen were intermediate. Female deer from Famenne would be expected to have a greater growth coefficient associated with their higher asymptotic values. But this is not the case in our study. Female deer from Famenne had actually a greater growth coefficient for PL but not for body mass or DL, and differences were only significant between Famenne and Hertogenwald. It could be suggested that, according to the principle of energy allocation (Levins 1968 quoted in Blondel 1979), in Famenne, a particularly good quality habitat, a relatively more important part of energy could have been spent in skeletal growth during early development, before being fully useful to muscular and fat development later in life. And, in Hertogenwald, the poorest habitat, the skeletal growth rate of female calves could have been delayed when conditions were less favourable thus allowing the allocation of relatively more energy to the growth of muscular and fat tissue (Verme and Ozoga 1980, Clutton-Brock et al. 1982, de Crombrugghe et al. 1989, Clutton-Brock 1991): this could explain the shorter PL growth period for Famenne compared with that for Hertogenwald. On the other hand, female deer of the poorest habitat, i.e. Hertogenwald, had smaller growth coefficients of BM, DL and PL (difference were only significant for PL and between Hertogenwald and Famenne) associated with their smallest asymptotic values (but not significantly different from Eupen). It looks as if after exhibiting significantly lower BM and PL as calves and yearlings compared with the other areas (Table 3), adult female deer of Hertogenwald could partially recover thanks to their longer growth period (Klein 1964, Hesselton and Sauer 1973).

\section{Management implication}

The variation of the different parameters studied showed the same trend as the range quality value of Ueckermann (1960), but seems not to be influenced by the percentage of overpopulation in Elsenborn and in the Famenne area (according to Table 1). However, if one had taken into account disturbance as a supplementary factor for determining this range quality value, then Elsenborn, a military domain of $2.350 \mathrm{ha}$, with an exceptional interspersion of cover and feeding areas in its summer range, and the study area of Famenne, both having a lot of areas with limited access to man, should have had a higher carrying capacity than that assessed by Ueckermann's (1960) rating system.

Acknowledgements: We thank the local services of ther"Direction générale des Ressources naturelles et de l'Environnement, Division Nature et Forêts (Inspections de Verviers et de Malmédy)' and of the 'Donation royale' for their help in collecting the material analysed in this paper. We are grateful to E. Le Boulengé and anonymous reviewers for critical reading of and constructive comments on this paper and thank L. Wauters for the translation of an earlier version of this manuscript.

\section{References}

Ahlen I. 1965. Studies on red deer, Cervus elaphus L., in Scandinavia. III. Ecological investigations. Viltrevy 3: 177-376. 
Beninde J. 1937. Zur Naturgeschichte des Rothirsches. Vlg Dr P. Schöps, Leipzig: 1-123.

Blondel J. 1979. Biogéographie et écologie. Masson, Paris: 1-173.

Brisbin I. L., Jr and Lenarz M. S. 1984. Morphological comparisons of insular and mainland populations of Southeastern white-tailed deer. Journal of Mammalogy 65: 44-50.

Brisbin I. L., Jr, Collins C. T., White G. C. and McCallum D. 1987. A new paradigm for the analysis and interpretation of growth data: the shape of things to come. Auk 104: 552-554.

Brisbin I. L., Jr, White G. C. and Bush P. B. 1986a. PCB intake and the growth of waterfowl: multivariate analyses based on a reparameterized Richards sigmoid model. Growth 50: 1-11.

Brisbin I. L., Jr, White G. C., Bush P. B. and Mayack L. A. 1986b. Sigmoid growth analyses of wood ducks: the effects of sex, dietary protein and cadmium on parameters of the Richards model. Growth 50: 41-50.

Buchli Ch. (1979). Zur Populationsdynamik, Kondition und Konstitution des Rothirsches (Cervus elaphus L.) im und um des Schweizerischen Nationalpark. Inaugural-Dissertation Universität Zürich: 1-99+1-22.

Chesser R. H. and Smith M. H. 1987. Relationship of genetic variation to growth and reproduction in white-tailed deer. [In: Biology and management of the Cervidae. C. M. Wemmer, ed]. Smithsonian Institution Press, Washington, D. C.: 168-177.

Clutton-Brock T. H. 1991. Sport and wise use of ungulate populations. Gibier Faune Sauvage 8: 309-317.

Clutton-Brock T. H. and Albon S. D. 1983. Climatic variation and body weight of red deer. Journal of Wildlife Management 47: 1197-1201.

Clutton-Brock T. H., Guinness F. E. and Albon S. D. 1982. Red deer. Behavior and ecology of two sexes. University of Chicago Press, Chicago: 1-378.

Crombrugghe S., de 1964. Untersuchungen über die Reproduktion des Rotwildes in den Niederlanden. Zeitschrift für Jagdwissenschaft 10: 91-101.

Crombrugghe S., de 1976. La détermination de l'âge chez le Cerf. Groupe Travail Etude Equilibre forêt-gibier, Louvain-la-Neuve: 1-23.

Crombrugghe S., de, Bertouille S. and Berthet P. 1989. Masse corporelle et développement du maxillaire inférieur des faons du Cerf (Cervus elaphus L.) comme bioindicateurs des relations "Cerf-milieu”. Gibier Faune Sauvage 6: 261-277.

Crombrugghe S., de and Herman R. 1989. Suivi d'un cerf pélerin sur le Plateau des Hautes-Fagnes entre 1983 et 1988. Cahiers d'Ethologie appliquée 9 (1): 1-18.

Debouche C. 1977. Application de la régression non linéaire à l'étude et à la comparaison de courbes de croissance longitudinales. Thèse de doctorat, Faculté des Sciences Agronomiques de Gembloux, Belgique: $1-304$.

Eiberle K. 1965. Beitrag zur Qualitätskontrolle beim Rehwild. Schweizerische Zeitschrift für Forstwesen 9: 740-752.

Fandos P. and Vigal C. R. 1988. Body weight and horn length in relation to age of the spanish wild goat. Acta Theriologica 33: 339-344.

Fendley T. T. and Brisbin I. L. 1977. Growth curve analyses: a potential measure of the effects of environmental stress upon wildlife populations. Proceedings of XIIIth IUGB Congress, Atlanta: $337-350$.

Frampton C. M. and Nugent G. 1992. Age and sex independent comparisons of morphological measurements. Growth, Development and Aging 56: 45-52.

Fuller T. K., Pace R. M. III., Markl J. A. and Coy P. L. 1989. Morphometrics of white-tailed deer in north central Minnesota. Journal of Mammalogy 70: 184-188.

Gobbe V. 1971. Etude préliminaire sur certains caractères biométriques du Cerf (Cervus elaphus L.). Mémoire de fin d'études, Université Catholique de Louvain: 1-98.

Hesselton W. T. and Sauer P. 1973. Comparative physical condition of four deer herds in New York according to several indices. New York Fish and Game Journal 20: 77-107. 
Illius A. W. and Gordon I. J. 1990. Variation in foraging behaviour in red deer and the consequences for population demography. Journal of Animal Ecology 59: 89-101.

Kingsley M. C. S. 1979. Fitting the von Bertalanffy growth equation to Polar bear age weight data. Canadian Journal of Zoology 57: 1020-1025.

Klein R. 1964. Range-related differences in growth of deer reflected in skeletal ratios. Journal of Mammalogy 45: 226-235.

Langvatn R. (ed.) 1977. Criteria of physical condition, growth and development in Cervidae, suitable for routine studies. Nordic Council for Wildlife Research, Stockholm: 1-27.

Langvatn R. 1986. Size and relationships in Norwegian red deer (Cervus elaphus atlanticus, Lönnberg). Symposium Rotwild. International Council for Game and Wildlife Conservation, Graz: 2: 244-267.

Langvatn R. and Albon S. D. 1986. Geographic clines in body weight of Norwegian red deer: a novel explanation of Bergmann's rule? Holartic Ecology 9: 285-293.

Leberg P. L., Brisbin I. L., Jr, Smith M. H. and White G. C. 1989. Factors affecting the analysis of growth patterns of large mammals. Journal of Mammalogy 70: 275-283.

Leberg P. L., Smith M. H. and Brisbin I. L., Jr 1992. Influence of sex, habitat and genotype on the growth patterns of white-tailed deer. [In: The biology of deer. R. D. Brown, ed]. Springer-Verlag, New York: 343-350.

Lowe V. P. W. 1967. Teeth as indicators of age with special reference to red deer (Cervus elaphus) of known age from Rhum. Journal of Zoology, London 152: 137-153.

Lowe V. P. W. 1971. Some effects of change in estate management on a deer population. [In: The scientific management of animal and plant communities for conservation. E. A. Duffey, ed]. Britisch Ecological Society Symposium: 437-456.

Maillard D., Klein F. and Bolmont C. 1989. Caractéristiques morphométriques du cerf (Cervus elaphus ) d'après l'analyse des tableaux de chasse: cas de la forêt d'Arc-en-Barrois-Châteauvillain. Bulletin mensuel de l'Office national de la Chasse 131: 23-29.

Mitchell B., Staines B. W. and Welch D. 1977. Ecology of red deer. Natural Environnment Research Council. Institute of Terrestrial Ecology, Banchory: 1-74.

Müller-Using D. 1976. Rotwildalter-Merkblatt. Schalenwildausschuß des Deutschen Jagdschutz-Verbandes: 1-20.

Richards F. J. 1959. A flexible growth function for empirical use. Journal of experimental Botany 10, 29: $290-300$

Rieck W. 1955. Die Setzzeit bei Reh-, Rot-, und Damwild in Mitteleuropa. Zeitschrift für Jagdwissenschaft 1: 69-75.

Roseberry J. L. and Klimstra W. D. 1975. Some morphological characteristics of the Crab Orchad Deer herd. Journal of Wildlife Management 39: 48-58.

SAS 1985. SAS user's guide: statistics. Version 5. SAS Inst. Inc., Cary, North Carolina: 1-599.

Sokal R. R. and Rohlf F. J. 1981. Biometry. W. H. Freemaan and Company, New York: 1-859.

Teillaud P., Bon R., Gonzales G., Shaal A., Ballon P. and Campan R. 1991. Le Cerf. Les Ongulés sauvages de France. Revue d'Ecologie (Terre Vie) suppl. 6: 185-217.

Thome H. 1980. Vergleichend-anatomische Untersuchungen der prae- und postnatalen Entwicklung und der funktionellen Veränderungen des Uterus von Rotwild (Cervus elaphus Linne, 1758) sowie Alterberechnungen an Feten dieser Art. Schriften des Arbeitskreises für Wildbiologie und Jagdwissenschaft an der Justus Leibig-Universität Gießen 6: 1-119.

Ueckermann E. 1960. Wildstandsbewirtschaftung und Wildschadensverhütung beim Rotwild. Verlag Paul Parey, Hamburg und Berlin: 1-162.

Verme L. J. and Ozoga J. J. 1980. Effects of diet on growth and lipogenesis in deer fawns. Journal of Wildlife Management 44: 315-324.

Von Raesfeld F. 1964. Das Rotwild. Verlag Paul Parey, Hamburg und Berlin: 1-389.

Western D., Moss C. and Georgiadis N. 1983. Age estimation and population age structure of elephants from footprint dimensions. Journal of Wildlife Management 47: 1192-1197. 
White G. C. and Brisbin I. L. 1980. Estimation and comparison of parameters in stochastic growth models for barn owls. Growth 44: 97-111.

Zullinger E. M., Ricklefs R. E., Redford K. H. and Mace G. M. 1984. Fitting sigmoidal equations to mammalian growth curves. Journal of Mammalogy 65: 607-636.

Received 7 March 1994, revised 9 January 1995, accepted 16 January 1995. 